\title{
EL DERECHO A LA SALUD EN COLOMBIA: EVOLUCIÓN Y DEFENSA FRENTE A UN ESTADO QUE DISTA DE SER GARANTE
}

\author{
THE RIGHT TO HEALTH IN COLOMBIA: EVOLUTION AND DEFENSE AGAINST \\ A STATE THAT IS FAR FROM BEING A GUARANTOR
}

\author{
José Domingo Julio Pretelt \\ Recibido para publicación: Mayo 3 de 2017 - Aprobado para publicación: Junio 28 de 2017
}

\begin{abstract}
RESUMEN
En Colombia, el proceso y manejo que se le ha dado al derecho a la salud no ha sido uniforme. Antes de la sentencia T-760 de 2008, ya el derecho a la salud existía consagrado directa e indirectamente en la Constitución Política de 1991, en varios de sus artículos, entre ellos el artículo 44, 48, 49, 365 y 366 , entre otros relacionados. Pese a ello, las vulneraciones sistemáticas realizadas al derecho a la salud de los colombianos hicieron que en el país hubiera un viraje en la forma de cómo garantizar la salud y es así como este derecho fue adecuando a las intenciones del constituyente y posteriormente tomando una posicion categórica por los honorables jueces de la República, a tal punto que la salud en Colombia, pasó de ser un derecho social, económico y cultural a ser un derecho fundamental por conexidad y finalmente un derecho Fundamental autónomo.

En este artículo, veremos un breve resumen de su evolución y los mecanismos actuales para defenderla, así como posibles formas de defender la salud en Colombia teniendo en cuenta la normativa nacional e internacional vigente.
\end{abstract}

Palabras clave: Estado, derecho, riesgo, tutela.

\begin{abstract}
In Colombia, the process and management that has been given to the right to health has not been uniform. Prior to the T-760 ruling of 2008, the right to health was already directly and indirectly enshrined in the Political Constitution of 1991, in several of its articles, including articles 44, 48, 49, 365 and 366, among others. related Despite this, the systematic violations of the right to health of Colombians meant that there was a change in the way of how to guarantee health in the country, and that is how this right was adapted to the intentions of the constituent and then taking a position categorical by the honorable judges of the Republic, to the point that health in Colombia, went from being a social, economic and cultural right to be a fundamental right for connectedness and finally a fundamental right autonomous.
\end{abstract}

In this article, we will see a brief summary of its evolution and the current mechanisms to defend it, as well as possible ways of defending health in Colombia taking into account current national and international regulations.

Keywords: State, law, risk, guardianship.

Enfermero Magister en Salud Pública, Especialista en Gerencia de la Calidad y Auditoría en Salud. Email: Josedomingo79@yahoo.es 


\section{EVOLUCIÓN DEL DERECHO A LA SALUD}

Frente a la evolución del derecho a la salud en el mundo, la Organización de Naciones Unidas (ONU) a través de la Organización Mundial de la Salud (OMS), establece que "la salud es un estado de completo bienestar físico, mental y social y no solamente la ausencia de afecciones o enfermedades (...) el goce del grado máximo de salud que se pueda lograr es uno de los derechos fundamentales de todo ser humano sin distinción de raza, religión, ideología política o condición económica o social (...) considerada como una condición fundamental para lograr la paz y la seguridad (1).

Así mismo, la Declaración Universal de Derechos Humanos, dispone que "toda persona tiene derecho a un nivel de vida adecuado que le asegure, así como a su familia, la salud y el bienestar, y en especial la alimentación, el vestido, la vivienda, la asistencia médica y los servicios sociales necesarios (...) (2).

En Colombia, en la época contemporánea la salud tiene su génesis en la constitución de 1991, específicamente en su artículo 49, el cual reza "La atención de la salud y el saneamiento ambiental son servicios públicos a cargo del Estado. Se garantiza a todas las personas el acceso a los servicios de promoción, protección y recuperación de la salud. Corresponde al Estado organizar, dirigir y reglamentar la prestación de servicios de salud a los habitantes y de saneamiento ambiental conforme a los principios de eficiencia, universalidad $\mathrm{y}$ solidaridad. (...)" (3).

Por su parte, en la evolución que le han dado los honorables jueces de la Republica a través de la jurisprudencia de la Corte Constitucional, se ha sostenido dos posiciones; en primerlugar, se consideró que la protección al derecho a la salud dependía de si existía relación con otro derecho de mayor envergadura (vida, dignidad humana o integridad personal), esta posición es la que usualmente se conoció como conexidad; en un segundo lugar, se halla que la protección al derecho a la salud vía tutela, (4), tenía lugar cuando el accionante fuera un sujeto de especial protección, por lo que en esta posición, lo importante era determinar si se trataba, por ejemplo, de un niño, una persona de la tercera edad, un discapacitado, u otro sujeto cualificado taxativamente por la norma sustancial.; finalmente, con la sentencia T 760 de 2008, la Corte empezó a reconocer que el derecho a la salud era un derecho autónomo a otros derechos y que no sólo no dependía de estos, sino que no era necesario que siempre el tutelante fuera un sujeto de especial protección, por lo que el derecho a la salud, debía ser considerado fundamental en sí mismo(5).

De acuerdo a lo anterior, y gracias al avance de la jurisprudencia, fue en la sentencia C- 313 de 2014, donde se reconoció la fundamentalidad autónoma del derecho a la salud en Colombia, seguidamente ratificado por la Sentencia T$361 / 14$, donde se establece que "El derecho a la salud es un derecho fundamental de todos los habitantes del territorio nacional que debe ser respetado y protegido $y$, que puede ser invocado a través de la acción de tutela cuando este resultare amenazado o vulnerado, para lo cual, los jueces constitucionales pueden hacer efectiva su protección y restablecer los derechos vulnerados"(6). Bajo este precepto, es de anotar que el derecho a la salud, tiene una doble connotación al ser un derecho fundamental y al mismo tiempo un servicio público. Así las cosas, la salud tiene dos facetas distintas, que se encuentran estrechamente ligadas: por una parte, se trata de un servicio público vigilado por el Estado; mientras que, por la otra, se configura en un derecho que ha sido reconocido por el legislador estatutario como fundamental, de lo que se predica, entre otras, su carácter de irrenunciable. Además de dicha condición, se desprende el acceso oportuno y de calidad a los servicios que se requieran para alcanzar el mejor nivel de salud posible (7).

Por otro lado y en apoyo a lo dicho anteriormente, se debe recordar que son fines esenciales del Estado: servir a la comunidad, promover la prosperidad general y garantizar 
José D. Julio P. - Evolución y defensa frente a un estado que dista de ser garante

la efectividad de los principios, derechos y deberes consagrados en la Constitución; (...). Las autoridades de la República están instituidas para proteger a todas las personas residentes en Colombia, en su vida, honra, bienes, creencias, y demás derechos y libertades. Frente a estas explicitas indicaciones del Articulo 2 de la Carta Magna de Colombia, se puede ver claramente que la obligación de seguridad y protección del Estado es clara y precisa. Pues, es este el encargado de brindar la seguridad a todos los residente en el país (8). En este caso entendida la salud, como parte de esa seguridad que debe brindar el Estado a sus habitantes en el territorio nacional.

En cuanto al ámbito internacional, se ha destacado que este derecho implica que se le asegure a las personas, tanto individual como colectivamente, las condiciones necesarias para lograr y mantener el "más alto nivel posible de salud física y mental". Para ello, sin duda alguna, es necesario prever desde el punto legal y regulatorio, condiciones de acceso en todas sus facetas, desde la promoción y la prevención, pasando por el diagnóstico y el tratamiento, hasta la rehabilitación y la paliación. Por esta razón, se ha dicho que el acceso integral a un régimen amplio de coberturas, es lo que finalmente permite que se garantice a los individuos y las comunidades la mejor calidad de vida posible (9).

\section{DEFENSA DEL DERECHO A LA SALUD}

Por tratarse de un derecho fundamental, autónomo y además un servicio público a cargo del Estado, asume este una posición de garante, entendida esta como "aquélla situación en que coloca el ordenamiento jurídico a un determinado sujeto de derecho, en relación con el cumplimiento de una específica obligación de intervención, de tal suerte que cualquier desconocimiento de ella acarrea las mismas y diferentes consecuencias, obligaciones y sanciones que repercuten para el autor material y directo del hecho (10).

De este artículo se puede extraer entonces que el Estado Colombiano, en su obligación constitucional frente al derecho a la salud, está obligado a dar las garantías necesarias para que goce del más alto nivel de bienestar de sus habitantes, (salud), Por lo que si este no se da y por el contrario se vulneran los derechos fundamentales de las personas por acción u omisión, a la luz de los elementos facticos y jurídicos, se puede constituir al Estado Colombiano como generador de responsabilidad extracontractual frente a las personas que se vean afectadas en el restablecimiento de su salud, siempre y cuando no haya eximentes de responsabilidad.

Dentro de algunas fuentes para imputar dicha responsabilidad al Estado se halla el daño antijurídico por falla en el servicio, por la omisión en el cumplimiento del deber de vigilancia y protección que el Estado está obligado a prestar para asegurar la salud, la vida y seguridad de sus ciudadanos. Otra de las fuentes es la teoría del riesgo previsible y evitable frente a todas aquellas patologías donde se demandaba un deber objetivo de cuidado y el Estado o sus entidades, jamás ejecutaron las acciones eficaces pero sobre todo pertinentes y oportunas para evitar un desenlace fatal o una complicación evitable, por ejemplo aquellos casos de depresión endógena o intentos de suicidio previos que en ultimas por no tratarse oportuna o pertinentemente se desencadenan en un suicidio consumado.

Por último, desde el plano internacional se podría incluso endilgar responsabilidad internacional al Estado bajo las teorías existentes para la misma, pues desde la teoría del riesgo creado, se le puede aplicar ya que generalmente el riesgo se materializa por la falla del servicio de las EPS, que son entidades creadas por el Estado Colombiano mediante la ley 100 de 1993 (11). En cuanto a la teoría de la Complicidad y Aquiescencia, es difícil negarse, puesto que el Estado conoce de primera mano a través de sus entidades (Hospitales, EPS, Secretarias de salud Municipales, Seccionales, Distritales, Ministerio de salud, Superintendencia de 
salud y el Instituto nacional de salud) los datos de su población (12), y conoce además los antecedentes (13), de poblaciones particulares como los que se intentan suicidar, por cuanto el intento de suicidio es un evento de enteres epidemiológico, pero además, no solo es responsable porque conoce, sino porque está obligado constitucionalmente a concurrir eficazmente frente este tipo de población, entre otros. (Rips y Sivigila).

Para finalizar, en lo referente a la teoría del riesgo previsible y evitable, es preciso recordar que en la actualidad con la evolución de la ciencias sociales y humanas, sobre todo las ciencias de la salud, se tiene evidencia científica que indica que muchas patologías como el suicidio, el infarto agudo al miocardio y la diabetes mellitus, entre otras, no son eventos que suceden al azar, pues antes de su materialización las personas lo manifiestan de diferentes formas y muchos consultan durante varias semanas, meses e incluso años al sistema, lamentablemente su manejo inadecuado o en otras ocasiones la no adherencia hace que estos eventos o patologías se vuelva inevitables y desencadene incluso un fatal desenlace como la muerte.

Pese a lo dicho es de recordar que aunque puede aplicarse responsabilidad al Estado o incluso a particulares frente al desenlace no deseado de una condición de salud, es obligación de todo los habitante de Colombia dar cumplimiento a lo establecido en el artículo 49 de la constitución en su parte final "Toda persona tiene el deber de procurar el cuidado integral de su salud y la de su comunidad." y lo que establece la Ley 1751 de 2015, ley estatutaria de salud, que especifica en su artículo 10 en lo referente a los deberes de los ciudadanos, literal a "Propender por su autocuidado, el de su familia y el de su comunidad".

\section{REFERENCIAS}

1. Constitución de la Organización Mundial de la Salud.

2. Declaración Universal de los Derechos Humanos. Art. 25

3. Constitución política de Colombia, 1991:

Artículo 49.

4. Constitución política de Colombia, 1991

5. Corte Constitucional, sentencias T-760 de 2008 y T-153 de 2010

6. Sentencia C-313/14: Magistrado Ponente: Gabriel Eduardo Mendoza Martelo

7. Sentencia T-361/14: Magistrado Ponente: Jorge Ignacio Pretelt Chaljub

8. Sentencia T-121/15: Magistrado Ponente:

Luis Guillermo Guerrero Pérez

9. Constitución política de Colombia, 1991:

Artículo 2.

10. Sentencia T-121/15: Magistrado Ponente: Luis Guillermo Guerrero Pérez

11. LÓPEZ Díaz, Claudia "Introducción a la Imputación Objetiva

12. Ley 100 de 1993. Articulo. 155 y 177

13. Decreto 3518 de 2006

14. Resolución 1531 de 2014 